\title{
Students' Experiences of PBL in Macroeconomics at Higher Education: A Case Study in Trinidad and Tobago
}

\author{
Rhonda Dookwah, Gabriel Julien ${ }^{2}$ \\ ${ }^{1}$ University of Trinidad and Tobago, West Indies \\ University of the West Indies, West Indies \\ ${ }^{2}$ gabrieljulien7@gmail.com
}

Received 23 August 2020; Accepted 2 September 2020; Published 8 September 2020

\begin{abstract}
This research highlights the experiences of sixteen undergraduates who studied Macroeconomics at a higher education institution in Trinidad and Tobago called Prestigious College. The students used the Problem-Based Learning (PBL) approach for the first time and were extremely excited and anxious about learning through the use of the PBL strategy. Furthermore, they were quite willing to deviate from the traditional instructional method to accept the PBL. A review of the existing literature within the local context, indicated that there is a dearth of information about the experiences of these undergraduates who study Macroeconomics, using the PBL approach at Prestigious College. Hence, their voices and opinions about their experiences are absolutely necessary since they can be a catalyst for the proper creation of policy and implementation of PBL in this country. Moreover, their voices and opinions answer the research question: What are students' experiences with Problem-Based Learning in the study of Macroeconomics at Prestigious College? Consequently, an action research which used a case study was employed to adequately ascertain their experiences. It involved semi-structured interviews with four focus groups. Data were collected, collated, analyzed and narrated using two major themes: PBL motivates learners and PBL facilitates self-directed learners. Recommendations strongly advocating student-centered strategies were also offered.
\end{abstract}

KEYWORDS: Problem-based learning, focus group, Macroeconomics.

\section{INTRODUCTION}

"PBL encourages persons to assist each other."

"PBL leads to a better understanding."

"It was a different learning experience. I was motivated to do the work."

These voices mentioned above undoubtedly express some of the experiences of sixteen undergraduates who were actively involved in the study of Macroeconomics using a ProblemBased Learning (PBL) approach, over twelve weeks. They were eager and excited about this new and innovative learning strategy and gave it their full cooperation. Furthermore, they were quite willing to sacrifice the traditional method to experience this innovation called PBL.

This research is an investigation about the experiences of these students who pursued a Macroeconomics course at Prestigious College. It is instructive to note that Macroeconomics is one of the core courses for students who read for a Bachelor of Education Degree and it is imperative that they pass it, in order to graduate. After much deliberation at the management level PBL became the preferred method of instruction at Prestigious College. However frequent informal discussions and observations of lecturers teaching Macroeconomics, disclosed that the more common form of teaching is the traditional teacher-centered approach. A review of the literature revealed that the teaching of Macroeconomics using the PBL instructional approach at this institution has never been explored and officially recorded. In addition, the experiences of these students were never documented. This dearth of information led to the case study on students' experiences who use PBL in the study of Macroeconomics at Prestigious College. Too often policies in education at Prestigious College are implemented with little or no consultation with students. Thus, the principal objective of this study is to allow them to express their opinions freely and honestly. In this way, their experiences could influence and assist policy makers if more programmes are realized through PBL. Hence, this study could help to point a possible way forward especially if more PBL options are offered.

Since qualitative research focuses chiefly on the naturalistic approach, it was chosen to conduct this research. More specifically, a case study, which incorporated semi-structured interviews was also utilized with four focus groups. Moreover, it was best suited to properly understand and accurately answer the research question: What are students' experiences with Problem-Based Learning in the study Macroeconomics at Prestigious College? In this discourse PBL was explained and a justification for action research was offered. Data collection procedures were outlined, data analysis process was described, findings were extensively explained and narrated 
with the use of two major themes: PBL motivates learners and PBL facilitates self-directed learners. Recommendations advocating the use of more student-centered strategies were offered.

\section{LITERATURE REVIEW}

Problem-Based Learning (PBL): The literature states that Problem-Based Learning (PBL) was first coined in 1969 at the Mc Master University in Canada (Barrows \& Tamblyn, 1980; Kim, 2019). It is fundamentally grounded in constructivism, which is a 20th century philosophical approach (Murphy, 2009). Constructivism is chiefly based on the premise that knowledge is constructed through interactions among a group of learners. This ought to be done through proper collaboration among peers in pursuit of the solution of original real-world problems (Cantürk-Günhan, Bukova-Güzel, \& Özgüranese, 2012).

Thus, Problem-Based Learning (PBL) represents a distinct and complete shift in the education process. According to the literature it involves moving away from the traditional instruction approach which is generally focused on the instructor in favour of a more student-centered one (Arul, 2007; Schmidt, 1983). Hence, to concretize this studentcentered method, PBL offers three distinctive features: authentic experiences, self-directed learning, and group work (Boud \& Feletti, 2003).

The first feature, which comprises authentic experiences, assists students in comprehending the context within which the knowledge is to be applied. The basis of this learning task is problem formulation and a deliberate attempt to find solutions to it. The facilitator begins the process by presenting a realworld problem. This initiative stimulates dynamism, provokes cognition, and motivates students to pursue solutions to the open-ended problem (Wijnen et al., 2018).

As noted in the literature, self-directed learning, the second feature, permits students to take responsibility for their own learning (Cantürk-Günhan et al., 2012). However, they must be aware of their knowledge gaps and own limitations. They also need to accumulate all possible information necessary. This includes their wealth of experiences as well as all learning and skills gathered from other courses. In addition, they must engage in relevant research to gather pertinent information and thus, solve the problem.

Group work, the third criteria encourages and motivates students to actively engage with their peers. In doing so they freely express their opinions and ideas. Learning becomes dynamic and engaging and thus, cognition is evident (CantürkGünhan, et al., 2012).

In addition to Problem-Based learning, recent educational innovations also endorse the following two learning strategies: the flat classroom project (Davis \& Lyndsay, 2007), and the flipped classroom model (Lage, Platt, \& Treglia, 2000). The flat classroom project is a global collaborative initiative, for students in the United States school grades 3 to 12, which uses Web 2.0 tools to promote international creative collaboration and communication between students in classrooms around the world. The flipped classroom promotes a form of blended learning. In this model, the orthodox teaching approach is inverted, with students getting their instruction in the evening at home by watching pre-recorded lectures at their own pace, but still able to communicate with classmates and the instructor online (Lage et al., 2000). They complete discussions, homework, laboratories, and tests in class under the teacher's guidance.

During a Dakar conference prominent academics revised the framework for action to meet basic learning needs for all by 2015 . They also strongly advocated that there ought to be change with instructional approaches (Patankar, 2011; UNESCO, 2000). Furthermore, they recommended that tertiary level instructors devote more meaningful time to teaching and make greater use of student-centered learning methods. In addition, they suggested that less focus be placed on explicit instruction (Patankar, 2011; Watts \& Schaur, 2011).

This student-centered approach is a direct result of innovation and research through educators who had a keen interest in promoting best practices at higher education (Patankar, 2011; UNESCO, 2000; 2011). The call to implement student-centered education was accepted globally. Traditional education which tend to stereotype students as 'surface' learners was also questioned (Drinkwater \& Smethurst, 2011; Patankar, 2011; Watts \& Schaur, 2011). The numerous calls for changes in instructional approaches caused international investigations into the learning styles and classroom behavior of students. Some studies have concluded that students portray themselves as mainly a homogeneous group of passive learners who rely on rote learning and memorization (Mergendoller et al., 2000; Patankar, 2011). They lack critical thinking skills and are not "deep learners" (Patankar, 2011, p. 24). Darling-Hammond (2013) clearly highlighted that classroom instruction and improvement in teaching are receiving increased attention in colleges and universities worldwide. Moreover, researchers have reported that the study of Economics discouraged cooperation among students, who tend to prefer to work on their own, rather than in groups, in order to understand and clarify difficult concepts (Iida \& Oda, 2011; Mergendoller et al., 2000). Hence, these and other findings should be tested via studies in the local context. The following segment describes a typical PBL intervention at Prestigious College.

A typical PBL intervention was generally conducted during one semester. The first two weeks of the PBL sessions, are aimed at introducing and training the students in their new roles. They receive training as: group leaders, note takers and presenters. A review of the literature suggested that PBL classes begin with the facilitators presenting a group of students with complex problems (Stefanou et al., 2013). These problems must satisfy two basic criteria. One, they require 
more information because they are ill-defined. Two they are complex and thus, do not have a single correct answer. Hence, students must be willing to be flexible and collaborate because new information is constantly generated during classes. Moreover, this dynamic process fosters interest as well as stimulates controversy because it is open-ended, complex and requires students to participate fully (Cantürk-Günhan et al., 2012). In keeping with the criteria suggested by previous authors, students were given ill-defined and open-ended problems during this Macroeconomics study. It is against this background that this qualitative research was conducted.

\section{METHODS AND PROCEDURE}

Qualitative research: Tewksbury (2009) together with Leedy and Ormrod (2018) stated that qualitative research provides in-depth, detailed information and explores issues in their particular scenario. They further stated that it attempts to clarify issues and gain deep insight by asking questions such as: How many times? In what ways? Why so regularly? Similarly, Meyer (2000) noted that action research involves a cyclical process of data collection, reflection, and analysis and maintained that the strength of this research lies in its focus on generating solutions to practical problems. Furthermore, it also empowers practitioners, by getting them to actively engage in the research (Merriam \& Tisdell, 2016). Reason and Bradbury (2006) described action research as an approach that is used in designing studies and it also seeks both to inform and influence practice. Creswell (2018) alluded to the fact that qualitative research is useful because researchers can explore and comprehend in greater detail what respondents convey. Since one of the principal aim of qualitative research is to explore, understand and represent the experiences, and actions of participants, it was specifically chosen for this research. Action research, in particular the naturalistic perspective, was also considered. Data were collected during a semester and also during the normal teaching/learning interactions. In addition, semi-structured interviews were also utilized.

Semi-structured interviews: Before the data collection process, a semi-structured interview was designed and scheduled. Each of the four focus groups was interviewed separately and interviews lasted 30 to 45 minutes. This was deliberately done to heed the guidelines of Robson (2002). He stated that although interviews can be time consuming, 30 to 45 minutes allow participants the comfort and flexibility to speak freely. Hence, they are more likely to yield valuable and pertinent information. Conversely, interviews that extend beyond an hour may reduce participants' willingness to be a part of the research.

Semi-structured interviews provided a clearer understanding of the experiences of these students. Interviews were carefully selected because researchers felt that they would allow students to speak without inhibition and thus, address the research question: What are students' experiences with ProblemBased Learning in the study Macroeconomics at Prestigious
College? Thus, semi-structured interviews with four focus groups were selected because they allowed researchers to explore experiences and opinions among students.

Semi-structured interviews gave students the great freedom to communicate spontaneously. In addition, researchers were also able to interact directly with them and thus seek clarification with follow-up questions. They also allowed researchers to gain information from verbal and non-verbal responses. In this way researchers were able to comprehend the nuances which added a deeper level of meaning. Furthermore, these responses addressed the research question: What are students' experiences with Problem-Based Learning in the study of Macroeconomics at Prestigious College?

During the interview process, notes of the various responses of students were documented immediately. Interviews were transcribed as soon as they were completed. This was deliberately used to improve accuracy and maintain the integrity of the data collected (Creswell, 2018).

The experiences of students were transcribed into an Excel worksheet for easy retrieval, reading, coding and placing into themes, closely following the stages outlined by Creswell (2018). Two general headings emerged: PBL motivates learners and, PBL facilitates self-directed learners.

The interview process also allowed the researchers to gather demographic data from participants: Age range, gender, marital status and enrolment status. Students' previous experiences with PBL were recorded as a categorical variable for further analysis. Data collection was done through regular and consistent fieldwork. The days and the hours of contact were deliberately chosen to accommodate the students. Data were collected during students' time-table allocation for their study of Macroeconomics.

To complement this research, a case study was chosen because it was felt that this research strategy would provide an in-depth multi-faceted understanding about the experiences of these 16 undergraduates (prospective teachers) who were reading a course in Macroeconomics for their first degree, in their natural context.

Case Studies: They are holistic inquiries that seek to investigate a specific phenomenon within its natural setting. They are suitable for description, explanation and exploratory into arbitrary issues. According to Yin (2009) case studies explain, describe, illustrate, and enlighten. Yin (2009) also stated that they are empirical investigations and are chiefly based on knowledge and experience. They are also apt methods of qualitative research that intensely investigate a particular phenomenon within a specific context. In a similar way, Smith (1978, cited in Merriam \& Tisdell, 2016) posited that case studies are versatile and dynamic and provides a thorough and detailed examination of a phenomenon. It is also an intensive, holistic description and analysis of a single unit. Thus, Cohen, 
Morrison and Manion (2018) described it as an inquiry into precise scenarios within a real-life situation. To accentuate transparency, reliability and validity were maintained.

Reliability and Validity: Pilot and Beck (2014, cited in Connelly, 2016) hold the firm view that reliability in qualitative studies refers to the level of confidence in the data, interpretation, and methods used to support the quality. Additionally, Leung (2015, cited in Kee, 2020) stated reliability in qualitative research refers to exact replicability of the processes and the results. Thus, to enhance consistency, intercoder reliability was established. A high level of intercoder reliability indicated that both reliability and replicability were present, and these strengthen evidence that the results of this qualitative study were scientifically valid (Kurasaki, 2000, cited in Mac Phail et al., 2016, p. 199).

On the other hand, validity in qualitative research refers to the degree that the research measures what it purports to measure. It is not a single state, but rather the extent to which the researcher reports on data accurately (Cohen et al., 2018).
Thus, to ensure a high level of reliability and validity, responses from semi-structured interviews were immediately recorded and clearly documented into the EXCEL 2007 programme. In addition, participants were provided with a copy of the transcribed notes from audio recordings that enabled them to review detailed interview responses and hence verify accuracy. This continuous member-checking was employed to enhance the reliability and validity processes.

To further enhance the validity of the findings of this qualitative research, careful thought was given to data reproduction. This enhanced the true sentiments and experiences of students (Cohen et al., 2018). The following segment provides a description and background information of the students and explains how data were analyzed.

\section{DISCUSSION}

Who are these students? As mentioned above, a total of sixteen students comprised the entire class population which participated in this research. Demographics are represented in Table I.

Table 1: Demographic characteristics of participants

\begin{tabular}{|l|l|l|}
\hline Demographic Characteristics & Sub-categories & Percentages \\
\hline Age Group (years) & $21-25$ & 68.75 \\
& $26-30$ & 25 \\
& $31-35$ & 6.25 \\
\hline Gender & Female & 81.25 \\
\hline Marital Status & Male & 18.75 \\
\hline \multirow{2}{*}{ Enrolment Status } & Single & 87.5 \\
& Married & 12.5 \\
\hline Educational Attainment & Full-time & 87.5 \\
& Part-time & 12.5 \\
\hline & O' Levels & 100 \\
& Economics O' Level & 6.25 \\
\hline
\end{tabular}


The group was typically homogeneous in terms of their past knowledge on Macroeconomics. This added to the validity of the research since the lecturer did not have to address the idiosyncrasies among students. The only student who studied Macroeconomics at A' level was also the oldest in the group. In addition, he was unable to vividly recall some of the subject content during the semester. Variations reflected in the demographics also added to the richness in the data collected.

Duration of time using PBL strategies: Mention must be made that this was the first time that all sixteen students experienced the PBL strategy. They were all third-year undergraduates who read a Macroeconomics course. As documented in the introduction the duration of the course was one semester. There were fourteen sessions and classes were held on Monday from 12:30 - 3:30 p.m. On the thirteenth session, students had a final examination on the course content. On the fourteenth session, focus group interviews were held and during that interview they unanimously acclaimed that PBL motivates learners.

Analysis of data: A serious challenge lay in the effort to analyze accurately the experiences of these students, because very often their ideas were complex and complicated accounts and could only be best understood within their context. Since some of their perspectives were often couched in profound stories, in trying to analyze data researchers had to consider the form and context of these voices. To a large extent this involved examining how they conveyed their experiences. Researchers examined certain words, sentences, and linguistic features and focused attention on the way certain "slangs" were used. In addition, researchers paid close attention to when things were said, why they were said, and how they were said within the social context, to arrive at a comprehensive understanding of the experiences of these sixteen students.

The analysis presented in this research took a narrative form and used examples from the data to clarify issues and to show the relationship between analysis and the given context. This narrative form reflects its ever-developing nature as it describes the two major components of the students' experiences: PBL motivates learners and PBL facilitates self-directed learners.

PBL motivates learners: During the interview process students stated that PBL method was apt, succinct, and nonjudgmental. Since feedback was timely it inspired them to maximize their performance. Moreover, it encouraged excellent group collaboration and hence they were better prepared for examinations. It is instructive to note that the students also mentioned that since the research was an integral part of their activities, it was also relevant, appropriate and thus, motivated them to excel. Two students remarked that PBL provided: "Good understanding of content." and it caused them to become: "More involved in the learning of work." These findings are consistent with that of Barrows (1986); Hmelo-Silver (2004); Norman and Schmidt (1992). They affirm that one of the chief objectives associated with PBL is that it fosters intrinsic motivation in learners.

The sixteen undergraduates undoubtedly noted that the collaborative nature of PBL inspired them to become more engaged and hence, involved them in self-directed learning. They also carefully pointed out that the encouragement to do research, the clearer understanding of content, and the better information retention experienced certainly motivated them to keep focused. Some of them even remarked that they were: “... able to do the exam better." This is the exceeding satisfaction that students encountered with the PBL strategy. One student claimed that she: "Received a lot of feedback." Yet another enjoyed the PBL because: "Research was a part of our activities." During one of the group activities a student remarked that it encouraged 'social loafing.' This is a particularly important and valid statement. As this same student continued to actively participate more in group activities, his perspective changed. He viewed the PBL as a catalyst.

In the discussions with the focus groups, students were quite spontaneous and open with their responses. Some mentioned that: "Macroeconomics is hard, so we need more than board instructions." The way this statement was coined, coupled with the tone of voice clearly alerted researchers to the fact that these students were genuinely seeking motivation and encouragement. This was an extremely salient and potent message since it underscored the fact that learners were really motivated. Although they were somewhat dubious as to whether or not their appreciation for one instructional approach was superseded by PBL, nonetheless it motivated them to continue and thus maintain their focus. Similarly, when probed, they also admitted that although the language of Macroeconomics was not as straightforward as other disciplines such as Psychology, learning through the PBL method provided a tremendous source of encouragement. These three students provided an apt summary when they mentioned that PBL:

"Encouraged me to be responsible for my learning."

"Encouraged good group collaboration."

"Encouraged collaboration."

Huei-Chen and Blanchard (2019) also described PBL as one of those learning methods that motivates, incorporates, and engages students in the learning process. This also concurs corroborates some of the findings. The next segment continues to highlight the experiences of students using the heading: PBL facilitates self-directed learners.

PBL facilitates self-directed learners: Self-directed learning is normally conducted in a non-threatening environment. The students affirm that self-directed learning empowers and encourages them to become autonomous and take initiatives that will further foster their learning. They state that they can choose their learning styles, set their goals 
and ideals and sometimes conduct research independently. These experiences coincide with that of Akhand (2015). His research revealed that when students are taught in a selfdirected atmosphere and are afforded autonomy, their learning becomes exciting to such an extent that their esteem is boosted. Moreover, their cognition is heightened and performance increases. According to this research, self-directed learning has become a key focus in academic arena since it informs institutional success and PBL underscores this fact. Thus, these undergraduates claimed that while success is 1 attained it becomes more meaningful when it is self-directed.

The concept of self-directed learning has been defined differently among experts. The main understanding in this discourse is that students are actively engaged in the teaching/ learning process (Monrad \& Mølholt, 2017). The effectiveness of PBL on increasing students' educational attainments has been extensively studied for higher education students in nonexperimental settings (Thomas \& Gordon-Brydson, 2019; De Witte \& Rogge, 2016). Outcomes of self-directed studies indicated a significant positive effect on student achievements, motivation and hence student autonomy. Dos Santos, Padovan Otani, da Rocha and Sanches Marin (2019) undertook a theoretical and integrated literature review from four databases between 2010-2015. Their analysis of 36 articles disclosed that PBL enables student improvement of autonomy for learning, critical thinking skills and motivation for learning.

In this case study, students unanimously expressed a great satisfaction with the use of PBL since it encouraged self-directed learning. They undoubtedly stated that it really caused them to reflect profoundly on course content. Thus, it stimulated their minds and broadened their horizons to such a degree that they were able to properly engage in selflearning. Aristidou (2020) wrote comprehensively on the academic benefits and limitations of the PBL in his personal experience in the teaching of Mathematics. He stated that from his participation in a group observation and feedback from schools, they found that PBL enhanced pupils' skills, and thus fostered self-directed learning.

The four focus group students affirmed that self-directed learning also provided them with a deeper understanding of certain complex concepts. They described it as a renaissance and a new awakening since it was a different learning experience. They were motivated to do the work as well as they were encouraged to be responsible for their own learning. It further allowed them to ponder and unravel issues both individually and collectively. Many students supported both individual and group learning since they claimed that it motivated and encouraged them as well as heightened their leadership skills and thus, reinforced the fact that PBL is really ideal for selfdirected learners (Dos Santos et al., 2019; Mohamad, 2017; Rohanai et al., 2020). This reality was confirmed when a student stated that PBL enhanced: "Leadership role."
The students were also of the firm opinion that the study group formed during classes assisted them to think and perceive concepts beyond the learning experiences. Hence, they unanimously claimed that that PBL definitely facilitates self-directed learners. The undergraduates gave high prominence to the following experiences: They worked in groups, they engaged in private and individual study during class time and they used the internet as a source of reference material. Thus, the effective use of technology greatly enhanced the PBL strategies. The focus group findings also suggested that the students held positive views of the PBL since if fostered autonomy and self-directedness in the study of Macroeconomics.

Students stated that because PBL focuses on self-directed learning it enhanced their overall cognitive skills. Furthermore, they were able to think independently and hence became more responsible for their own learning. This outcome had significant implications for effective and sustained learning among the 16 undergraduate students in Macroeconomics.

PBL is important for these students because they are expected to be well equipped with numerous skills. Inherent in the PBL approach is content mastery. This means that students acquire knowledge and are in a better position to apply and share it. This is accomplished when they work in a collaborate and cooperative manner. In this way they are to assume responsibility for their own learning and engage in selfevaluation. As the participants stated, this PBL approach not only fosters self-directed learning, in fact, it has the potential to equip learners with multiple skills such as: problem-solving and creativity. Developing and inculcating these skills are necessary for these prospective teachers since they would have to execute them regularly in their profession.

Albanese and Mitchell (1993) concluded that students who experience PBL, study differently from those with exposure to the traditional learning. Moreover, PBL students are selfdirected learners. They are less likely to ask the teacher questions for information which they need to understand the content of the course. PBL students - because they are self-directed learners are more likely to use the library and other resources to study and appear to seek more resources to understand the content of the problem they are required to solve (Albanese \& Mitchell, 1993). Arul (2007), Liu et al (2006) together with Mergendoller et al (2000) reported on students' PBL experiences of self-directed learning, information retention, enhancing personal skills and collaborative learning. Much of what they described was exhibited by the students in this study. The following three students aptly captured the significance of the use of PBL. They further mentioned that it is ideal for self-directed learners:

"Allows for independent and group thinking at the same time." 
"It causes students to engage in self-learning."

"PBL encourages persons to assist each other."

\section{Conclusion}

Action research afforded researchers the great flexibility to interact informally with these sixteen undergraduates in their natural environment. Moreover, it also allowed the students to speak freely and spontaneously about their own experiences as they relate to the PBL strategies. Semi-structured interviews assisted researchers to maintain the focus and thus answer the research question. Data were collected, collated, and documented in a narrative form using two thematic headings: PBL motivates learners and, PBL facilitates self-directed learners. Recommendations advocating for the use of more student-centered education were offered.

\section{RECOMMENDATIONS}

From the foregone the following recommendations are suggested:

- More PBL learning strategies ought to be implemented in various courses for undergraduate students.

- Tertiary education students should be provided with more self-directed learning opportunities.

- A combination of traditional teaching and PBL should be offered for Macroeconomics

\section{CONFLICT OF INTERESTS}

Authors have no conflict of interests.

\section{REFERENCES}

1. Akhand, M. M. (2015). Project Based Learning (PBL) and Webquest: New Dimensions in Achieving Learner Autonomy in a Class at Tertiary Level. Journal of Pan-Pacific Association of Applied Linguistics, 19(2), 55-74. a. https://pdfs.semanticscholar.org/ b467/089d0422a83fe1d5715d837dd39d9fce4e7c.pdf

2. Albanese, M. A. \& Mitchell, S. (1993). Problem-based learning: A review of literature on its outcomes and implementation issues. Academic Medicine, 68(1), 52-81.

3. Aristidou, M. (2020). Project Based Learning: Are there any academic benefits for the teacher or students? Journal of Humanistic Mathematics, 10(1), 458-471. doi.org/10.5642/jhummath.202001.25

4. Arul, K.S. (2007, January). Making sense of Economics: Designing educational scenarios for Problem Based Learning. Paper presented at the conference organized by the University of Wales Ins. Cardiff in collaboration with the Higher Education Academy. U.S.A.

5. Barrows, H. S. \& Tamblyn, R. N. (1980). Problem-Based Learning: An approach to medical education. New York: Springer.

6. Barrows, H. S. (1986). A taxonomy of problem-based learning methods. Medical Education, 20, 481-486. doi:10.1111/j.1365-2923.1986. tb01386.x

7. Boud, D. \& Feletti, G. I. (2003). The challenge of problem-based learning (2nd ed.). USA: Kogan Page.

8. Cantürk-Günhan, B., Bukova-Güzel, E., \& Özgür, Z. (2012). The prospective mathematics teachers' thought processes and views about using Problem-based learning in statistics education International Journal of Mathematical Education in Science \& Technology, 43(2), 145-165. doi :10.1080/0020739X.2011.592611.

9. Cohen, L., Morrison, L., \& Manion L, K. (2018). Research methods in education (8th ed.). NY: Routledge.

10. Connelly, L. M. (2016). Trustworthiness in qualitative research. Understanding Research, 25(6).

11. h t t p s : // p d f s. s e mant i c s c holar.org/ b467/089d0422a83fe1d5715d837dd39d9fce4e7c.pdf

12. Creswell, J. W. (2018). Research design: Qualitative, quantitative, and mixed methods approaches (5th ed.). California: SAGE.

13. Darling-Hammond, L. (2013). Getting teacher evaluation right: What really matters for effectiveness and improvement? NY: Teachers College, Columbia University.

14. Davis, V. \& Lyndsay J. (2007). Flat Classrooms. Learning \& Leading with Technology, 35(1), 28-30.

15. De Witte, K., \& Rogge, N. (2016). Problem-Based Learning in Secondary Education: Evaluation by an Experiment. Education Economics, 24(1-2), 58-82. doi.org/10.1080/09645292.2014.966061.

16. Dos Santos, M. Z., Padovan Otani, M. A., da Rocha Tonhom, S. F., \& Sanches Marin, M. J. (2019). Degree in Nursing: education through problem-based learning. Revista Brasileira de Enfermagem, 72(4), 10711077. https://doi.org/10.1590/0034-7167-2018-0298

17. Drinkwater, D. \& Smethurst, J. (2011). Partnership Now: A Paradigm Shift in Education. Independent School, 70(3), 41-46.

18. Hmelo-Silver, C. E. (2004). Problem-based learning: What and how do students learn? Educational Psychology Review, 16, 235-266. doi:10.1023/B:EDPR.0000034022.16470.f3

19. Huei-Chen Lee, \& Blanchard, M. R. (2019). Why Teach With PBL? Motivational Factors Underlying Middle and High School Teachers' Use of Problem-Based Learning. Interdisciplinary Journal of Problem-Based Learning, 13(1), 1-18. https://doi.org/10.7771/1541-5015.1719

20. Iida, Y. \& Oda, S. H. (2011). Does economics education make bad citizens? The effect of economics education in Japan. Journal of Education for Business, 86, 234-239. doi:10.1080/08832323.2010.511303

21. Kee, C. L. (2020). Face to face tutorial, learning management system and WhatsApp group: How digital immigrants interact and engage in e-learning. Malaysian Online Journal of Educational Technology, 8(1), 18-35.

22. Kim, Y. J. (2019). Observational Application Comparing ProblemBased Learning with the Conventional Teaching Method for Clinical Acupuncture Education. Evidence-Based Complementary \& Alternative Medicine (ECAM), 1-6. doi.org/10.1155/2019/2102304

23. Lage, M., Platt. G., \& Treglia, M. (2000), Inverting the Classroom: A gateway to Creating an Inclusive Learning Environment, Journal of Economic Education, 31: 30-43

24. Leedy, P. D., \& Ormrod, J. E. (2018). Practical Research: Planning and Design (12th ed.). NJ: Prentice-Hall Inc.

25. Liu, M., Hsieh, P., Cho, Y., \& Schallert, D. L. (2006). Middle school students' self-efficacy, attitudes, and achievement in a computer-enhanced problem-based learning environment. Journal of Interactive Learning Research, 17, 225-242.

26. Mac Phail, C., Khoza, N., Abler, L., \& Ranganathan, M. (2016). Process guidelines for establishing intercoder reliability in qualitative studies. Qualitative Studies, 16(2), 198-212. doi: 10.1177/1468794115577012.

27. Mergendoller, J. R., Maxwell, N. L., \& Bellisimo, Y. (2000). Comparing problem-based learning and traditional instruction in high school Economics. Journal of Educational Research, 93(6), 374-382.

28. Meyer, J. (2000). Using qualitative methods in health-related action research. British Medical Journal, 320, 178-181.

29. Merriam, S. B., \& Tisdell, E. J. (2016). Qualitative research: A guide to design and implementation (4th ed.). San Francisco: Jossey - Bass.

30. Mohamad, H. B. (2017). The impact of Problem-Based Learning on students' competencies in Technical Vocational Education and Training. 
Aalborg Universitetsforlag.

31. Monrad, M., \& Mølholt, A.-K. (2017). Problem-Based Learning in Social Work Education: Students' Experiences in Denmark. Journal of Teaching in Social Work, 37(1), 71-86. https://doi.org/10.1080/08841233.2016.12 71382

32. Murphy, M. M. (2009). The history and philosophy of education: Voices of educational pioneers. Upper Saddle River, NJ: Pearson Education.

33. Norman, G. R., \& Schmidt, H. G. (1992). The psychological basis of problem-based learning: A review of evidence. Academic Medicine, 67, 557-565. doi:10.1097/00001888-199209000-00002.

34. Patankar, P. (2011). Teacher Education: Need of Paradigm shift from Behaviorism to Constructivism. Indian Streams Research Journal, 1(11), 23-25.

35. Robson, C. (2002). Real world research (2nd ed.). Oxford, UK: Blackwell.

36. Rohanai, R., Othman, H., Daud, K. A. M., Omar, N. H., Ahmad, M., Ismail, M. E., \& Sulaiman, A. (2020). Malaysian PBL Approaches: Shaping World-Class TVET Skills towards IR 4.0. International Journal of Psychosocial Rehabilitation, 24(2), 1716-1725.

37. Reason, P., \& Bradbury, H. (2008). The SAGE Handbook of Action Research: Participative Inquiry and Practice (2nd ed.). London: SAGE.

38. Schmidt, H. G. (1983). Problem-based learning: Rationale and description. Medical Education, 17(1), 11-16.

39. Stefanou, C., Stolk, J. D., Prince, M., Chen, J. C., \& Lord, S. M. (2013). Self-regulation and autonomy in problem- and project-based learning environments. Active Learning in Higher Education, 14(2), 109-122. https://doi.org/10.1177/1469787413481132

40. Tewksbury, R. (2009). Qualitative versus Quantitative Methods: Understanding Why Qualitative Methods are Superior for Criminology and Criminal Justice. Journal of Theoretical and Philosophical Criminology, 1 (1).

41. Thomas A., \& Gordon-Brydson, L.-C. (2019). Meeting 21st Century Needs in Higher Education: Creating a Model Teaching and Learning Unit for Institutions. Journal of Arts Science \& Technology, 12(1), 3-16.

42. UNESCO (2000). Final Report. World Education Forum. Senegal. UNESCO. www.unesco.org

43. UNESCO. (2011). Education for Sustainable Development in the Caribbean: An assessment of the progress made in ESD as of 2011. UNESCO Regional Bureau for Education in Latin America and the Caribbean: Chile.

44. Watts, M. \& Schaur, G. (2011). Teaching and assessment methods in undergraduate economics: A fourth national quinquennial survey. The Journal of Economic Education, 42(3), 294-309. doi:10.1080/00220485 .2011 .581956

45. Wijnen, M., Loyens, S. M. M., Wijnia, L., Smeets, G., Kroeze, M. J., \& Van der Molen, H. T. (2018). Is problem-based learning associated with students' motivation? A quantitative and qualitative study. Learning Environments Research, 21(2), 173-193. https://doi.org/10.1007/s10984017-9246-9

46. Yin, R. (2009). Case Study Research: Design and Methods (4th ed.). Thousand Oaks, CA: Sage Publications.

Citation: Rhonda Dookwah, Gabriel Julien, "Students' Experiences of PBL in Macroeconomics at Higher Education: A Case Study in Trinidad and Tobago". American Research Journal of Humanities and Social Sciences, vol 6, no. 1, 2020, pp. 1-8.

Copyright (c) 2020 Gabriel Julien, et al. This is an open access article distributed under the Creative Commons Attribution License, which permits unrestricted use, distribution, and reproduction in any medium, provided the original work is properly cited. 